\title{
COVID-19 Behind Bars
}

\section{Steven Zehr}

$\mathrm{W}$

hat has it been like being incarcerated during the COVID-19 pandemic? Well, it is the summer and we are not out of the woods yet. Fall and winter will soon be here and we are very concerned. Thankfully, we have been clear of COVID-19 cases here at Warkworth. As far as steps prisoners are taking to keep each other safe, it has been a mixed bag. Some prisoners are practicing social distancing and wearing masks but, as long as we remain virus free, protocols will continue to be relaxed. The real test will be when we get a case.

Earlier in the year, healthcare staff identified someone in our unit who was displaying COVID-19 symptoms. Accordingly, he was asked to self-isolate. When healthcare staff later came to check on him, they discovered he was in someone else's cell with five others playing some board game. He was removed only because he threatened staff, not because he was not isolating. Although I suggested isolating those five guys and wiping the unit down, it did not happen. Thankfully, however, his test results came back negative.

Here in Warkworth, we have two cohorts: units one and two are grouped together, and then units three, four and five. Units one and two work Monday and Tuesday, Wednesday is for cleaning all units, while units three, four and five work on Thursday and Friday. The Correctional Service of Canada (CSC) is trying to prevent the virus from spreading within our institution and, currently, no prisoners here have COVID-19. The only way any of us will get COVID-19 is from staff or instructors.

If someone from unit one or two gets COVID-19, chances are someone from unit three, four or five will get infected by the same person. How is this plan really protecting us from COVID-19 as a whole?

\section{ABOUT THE AUTHOR}

Steven Zehr is a writer and artist incarcerated at Warkworth Institution. He can be reached by mail at the following address:

Steven Zehr

Warkworth Institution

County Rd 29

P.O. Box 760

Campbellford, ON

K0L1L0 